\title{
Shades of the mirror effect: Recognition of faces with and without sunglasses
}

\author{
WILLIAM E. HOCKLEY, DAVID H. HEMSWORTH, and ANGELA CONSOLI \\ Wilfrid Laurier University, Waterloo, Ontario, Canada
}

\begin{abstract}
A mirror effect was found for a stimulus manipulation introduced at test. When subjects studied a set of normal faces and then were tested with new and old faces that were normal or wearing sunglasses, the hit rate was higher and the false alarm rate was lower for normal faces. Hit rate differences were reflected in remember and sure recognition responses, whereas differences in false alarm rates were largely seen in know and unsure judgments. In contrast, when subjects studied faces wearing sunglasses, the hit rate was greater for test faces with sunglasses than for normal faces, but there was no difference in false alarm rates. These findings are problematic for single-factor theories of the mirror effect, but can be accommodated within a two-factor account.
\end{abstract}

The mirror effect refers to the regularity of recognition memory in which classes of stimuli that are relatively easy to identify as old when old are also relatively easy to classify as new when new. In other words, the difference in discriminability is observed in both hit and false alarm rates rather than in only one of these measures. Glanzer and Adams (1985), in a review of 80 recognition experiments, showed that the mirror effect can be seen for a variety of stimulus manipulations (e.g., natural language word frequency, concreteness, meaningfulness, and pictures vs. words) and that it holds for both yes/no and forced-choice recognition test procedures.

The mirror effect has been extended to tests of associative recognition (Greene, 1996; Hockley, 1994) as well as discriminations of order (Greene, 1996) and frequency (Greene \& Thapar, 1994); it is also reflected in measures of response latency (Hockley, 1994). Hintzman, Caulton, and Curran (1994) have further demonstrated that dividing attention at test, or using a response-signal procedure to control processing time at retrieval, does not eliminate or attenuate the mirror effect. Hintzman et al. concluded that the mirror effect "may best be attributed to the inherent nature of the retrieval and judgment processes that underlie recognition memory" (p. 286).

Hintzman et al. (1994) further noted that the mirror effect has proven to be difficult to account for in the context of most current models of recognition memory. This is because most models view recognition memory in terms

This work was supported by a Natural Sciences and Engineering Research Council of Canada operating grant to W.E.H. A version of this paper was presented at the annual meeting of the Psychonomic Society, Chicago, November 1996. We thank Bennet B. Murdock for presenting the paper when W.E.H. was not able to attend the meeting. We also thank Robert Greene, James Bartlett, Wayne Donaldson, and an anonymous reviewer for their very helpful comments on an earlier version of this paper. Correspondence should be addressed to W. E. Hockley, Department of Psychology, Wilfrid Laurier University, Waterloo, ON, N2L 3C5 Canada (e-mail: whockley ( $a$ mach l. wlu.ca). of signal detection theory, in which new and old items are assumed to vary along a single dimension of familiarity or memory strength (see, e.g., Gillund \& Shiffrin, 1984; Hintzman, 1988; Hockley \& Murdock, 1987; Humphreys, Bain, \& Pike, 1989; Murdock, 1982). The problem for such models is to explain why the average strength of items from the more recognizable stimulus class is both greater when the items are old and less when the items are new than the average strength of old and new items from the less recognizable stimulus class.

One approach to this problem has been to assume that memory strength is rescaled so that the old and new item distributions for each stimulus class are ordered appropriately prior to the recognition decision. Gillund and Shiffrin (1984) proposed a rescaling procedure similar to the calculation of $z$ scores in which the familiarity of a test item is scaled against the estimated mean and standard deviation of the new item distribution of that class. Glanzer and his colleagues (Glanzer \& Adams, 1990; Glanzer, Adams, \& Iverson, 1991; Glanzer, Adams, Iverson, \& Kim, 1993; Kim \& Glanzer, 1993, 1994) have developed a rescaling approach in considerable detail in their attention-likelihood theory. In this theory, when the strength value of the test item is determined, the subject must decide whether that value came from the new or the old item distribution. This is accomplished by determining the likelihood ratio for the familiarity value. The likelihood ratios differ for items from the more and less recognizable stimulus classes. Attention-likelihood theory provides an account of the mirror effect but, like Gillund and Shiffrin's rescaling proposal, requires that the recognition system compute or estimate memory strength distributions for the different classes of stimuli.

Hintzman (1994) has proposed test-trial increment rescaling as an alternative rescaling procedure. The information used to rescale memory strength is generated item by item by relearning the probe on the test trial and comparing the strength of the probe after relearning to its initial strength. Rescaling based on relearning during 
test does not require subjects to generate or compute complete familiarity distributions for different stimulus classes.

A second approach to explain the mirror effect has been termed the "two-factor view" by Hintzman et al. (1994). In accounts of this type, one factor is assumed to determine the order of new items from each stimulus class, and a second factor determines the order of old items from each stimulus class (see, e.g., Glanzer \& Bowles, 1976; Hintzman, 1988; Hoshino, 1991; Wixted, 1992). For example, Hintzman (1988) and Hoshino (1991) have suggested a two-factor account of the mirror effect for word frequency. They assumed that high-frequency words are initially more familiar than low-frequency words, which would lead to a higher false alarm rate for highfrequency words. In addition, if low-frequency words are usually better encoded than high-frequency words during study, and if this encoding advantage is great enough to reverse the initial difference in familiarity, then the hit rate for low-frequency words would be greater than the hit rate for high-frequency words. Thus, these two factors combine to produce the mirror effect for word frequency.

Hockley (1996) proposed a more general two-factor account of the mirror effect based on the assumption that recognition decisions can be based on two different components or aspects of recognition memory-familiarity and recollection (see, e.g., Mandler, 1980, 1991; Tulving, 1985). In this view, differences in hit rate are due to greater recollection of items from the more memorable stimulus class and differences in false alarm rates are due to greater familiarity in the absence of recollection for items of the less memorable class.

Evidence for a two-factor interpretation of the mirror effect has been provided by Bartlett, Halpern, and Dowling (1995). They found a mirror effect in an episodic recognition task involving discrimination of traditional versus novel tunes that were musically equivalent. For both young and healthy elderly subjects, the hit rate was higher and the false alarm rate was lower for traditional tunes. In contrast, Alzheimer's (AD) patients did not show a mirror effect; they failed to reduce false alarms for familiar tunes. This pattern of results, as Bartlett et al. (1995) noted, are similar to those reported by Bäckman and Herlitz (1990), who found that elderly control subjects showed a mirror effect in an episodic recognition experiment favoring photographs of people who had been famous in the 1930s and 1940s compared with photographs of people famous more recently. AD patients, however, failed to demonstrate a mirror effect; both their hit and false alarm rates increased for the dated faces. Bartlett et al. (1995) suggested that AD patients, who suffer deficits in recollection and source monitoring, base their recognition decisions on global familiarity and are thus prone to false alarms for new items that are high in familiarity. Normal subjects, on the other hand, are better able to use information other than global, undifferentiated familiarity to make their recognition decisions.
A third approach in explaining the mirror effect is the response bias account. Hirshman (1995), for example, has suggested that the mirror effect arises from differences in the placement of the recognition decision criterion for different classes of stimuli. Thus, as the mean of the old distribution increases for the more memorable stimulus class, the placement of the decision criterion also increases (although not to the same extent as the mean of the old item distribution). Such changes would produce a mirror effect: Hits would increase because a larger proportion of the old distribution is to the right of the criterion, and false alarms would decrease because a smaller proportion of the new item distribution is above the criterion.

Hintzman et al. (1994) have characterized the prototypical mirror effect as a difference in the discriminability between two classes of stimuli that is accompanied by little or no difference in bias. Thus Hirshman's (1995) criterion shift account cannot provide an explanation of the prototypical mirror effect as defined by Hintzman et al. Nevertheless, Hirshman's bias account is considered here because appropriate criterion shifts can produce a mirrorlike pattern of results.

Greene (1996) has also suggested a response bias interpretation of the mirror effect. In Greene's response distribution account, subjects attempt to give roughly equal numbers of positive responses to items from each different stimulus class. Subjects would be more accurate in their positive responses for items from the more memorable class and less accurate in distributing positive responses across items from the less memorable class. An assumption of both Hirshman's and Greene's response bias accounts is that subjects are sensitive to the different stimulus classes.

Investigations of the mirror effect have been carried out using stimulus manipulations that are present both at study and at test. This procedure provides an opportunity for subjects to discern the different classes of stimuli prior to test. The initial goal of the present study was to find a manipulation that could be introduced at test that would produce a mirror effect. If, as Hintzman et al. (1994) concluded, the mirror effect is due to the inherent nature of the retrieval and judgment processes underlying recognition memory, then it should be possible to find such a manipulation.

In Experiment 1, subjects studied novel normal faces. At test, recognition memory for studied and new faces was examined. Half of the old faces and half of the new faces were normal, and half were wearing sunglasses. One prediction that could be made is that introducing sunglasses at test would decrease the familiarity, or the number of matching features, for both old and new faces, which would lead to lower hit and false alarm rates for faces with sunglasses than for normal faces. That is, sunglasses might act as a form of stimulus degradation.

A second prediction can be derived from the revelation effect, the phenomenon of recognition memory in 
which items that are initially only partially revealed, or distorted in some fashion, at test are more likely to be classified as old than are items that are presented intact (LeCompte, 1995; Luo, 1993; Peynircioğlu \& Tekcan, 1993; Watkins \& Peynircioğlu, 1990; Westerman \& Greene, 1996). If sunglasses act to distort or "disguise" test faces in a manner similar to that of other manipulations that produce the revelation effect, then both hit and false alarm rates should be higher for test faces with sunglasses. As it turned out, however, the sunglasses manipulation served to increase the false alarm rate but decrease the hit rate, thereby producing a mirror effect. ${ }^{1}$

A second purpose of the present study was to further test the two-component account of the mirror effect using the remember/know response paradigm. Tulving (1985) introduced this subjective response procedure to distinguish between two types of recognition decisions. Subjects are asked to classify old responses as either remember responses, which are accompanied by conscious recollection of details of the item's prior occurrence, or as know responses, which are associated with a feeling of familiarity in the absence of conscious recollection. A number of investigators have argued for the validity of this subjective discrimination (e.g., Conway \& Dewhurst, 1995; Dewhurst \& Conway, 1994; Gardiner, 1988; Gardiner \& Java, 1991, 1993; Gardiner, Java, \& RichardsonKlavehn, 1996; Gardiner \& Parkin, 1990; Kinoshita, 1995; Knowlton \& Squire; 1995; LeCompte, 1995; Parkin \& Russo, 1993; Perfect, Mayes, Downes, \& Van Eijk, 1996; Rajaram, 1993).

Recently, however, some investigators have questioned the interpretation of remember/know responses (Donaldson, 1996; Hirshman \& Master, 1997; Strack \& Forster, 1995). Hirshman and Master (1997) and Donaldson (1996) have argued that the pattern of results found in the remember/know paradigm can be fit by a single-factor signal detection type of model. Donaldson (1996) showed, in a meta-analysis based on data from 80 conditions in 28 experiments from 17 different published studies, that overall recognition performance (i.e., collapsing over remember and know recognition responses) produces similar estimates of $d^{\prime}$ and $A^{\prime}$ as does recognition performance conditionalized on remember responses. ${ }^{2}$ This finding suggests that remember responses, like highconfident responses, may represent recognition decisions made with a stricter decision criterion.

Hockley (1996), in an examination of the two-component account of the mirror effect, used the remember/ know response procedure to evaluate the separate contributions of familiarity and recollection. Hockley (1996) examined the effects of word frequency for item recognition and word concreteness for both item and associative recognition, and found that the hit rate advantage for low-frequency and concrete words was reflected entirely in remember responses. These findings replicated and extended the effects of word frequency on remember and know responses reported by Gardiner and Java (1990),
Kinoshita (1995), and Strack and Forster (1995). Hockley (1996) also found that the differences in false alarm rates were largely seen in know responses. This pattern of results supports a two-component account of the mirror effect. A similar pattern of results, however, was also obtained when a sure/unsure confidence judgment procedure was substituted for the remember/know response procedure. Furthermore, estimates of $d^{\prime}$ and $A^{\prime}$ were similar when calculated on overall recognition performance and when conditionalized only on remember or sure responses.

The remember/know response paradigm was used in Experiments 1 and 2 of the present study. Sure/unsure confidence judgments were used in Experiment 3 in order to compare the pattern of results from both response procedures. The results, thus, also provide a test of the generalizability of Donaldson's (1996) signal detection analysis of remember responses. Subjects may have difficulty distinguishing between remember and know bases of recognition in the typical verbal learning experiment because the relatively brief presentation of common words might not afford sufficient opportunity to encode rich, recollectable details of their occurrence. The encoding of novel faces, on the other hand, may better support the recollection of specific details. Faces, particularly if they appear wearing sunglasses, may also engender strong, accurate, and confident feelings of familiarity in the absence of recollection.

\section{EXPERIMENT 1}

\section{Method}

Subjects. The participants were 50 undergraduate students who volunteered for course credit or payment.

Apparatus and Stimuli. The stimuli consisted of color slides of faces of 37 male and female Caucasian undergraduate students enrolled in summer courses in 1994. The pictures were frontal views of the head and shoulder tops taken against the same neutral background. None of the males had facial hair, and none of the models were wearing adornments such as jewelry or hair ribbons. The models posed with a neutral expression. Two pictures were taken, one normally and one with the models wearing sunglasses. Every attempt was made for the two poses to be as similar as possible. All models wore the same white lab coat over their street clothes and the same pair of dark sunglasses. The stimuli were presented with a slide projector.

Procedure. Experiment 1 was run as a distractor task to occupy the first retention interval in a study conducted by Consoli (1996, Experiment 2). In Consoli's experiment, subjects studied a list of 96 random pairs of words with instructions to form associations between the two words of each pair. Following the study phase, subjects were given an immediate recognition test based on one third of the studied pairs, a second test 30 min later, and a final test $24 \mathrm{~h}$ later. Each test list consisted of 32 single words and 32 word pairs shown in a random order. The remember/know response procedure was used for each test. The instructions given to subjects were based on those described by Gardiner and Parkin (1990). Thus, subjects in Experiment 1 were familiar with the remenber/know response procedure.

The study phase of the face recognition experiment consisted of the presentation of 21 slides of normal faces. Each slide was shown for approximately $\mathrm{I} \mathrm{sec}$ with an interval of approximately $1 \mathrm{sec}$ be- 
tween slides. All subjects saw the slides in the same presentation order. Subjects were instructed to study the faces in preparation for a recognition test of the faces. After the study slides were shown, the experimenter engaged the subjects in conversation for $15 \mathrm{~min}$.

Near the end of the retention interval, subjects were reminded of the remember/know response instructions. They were then told that some of the new and old test faces would now be wearing sunglasses, but that they should try to make their decisions on the basis of whether or not the face had been presented in the study set. That is, they were asked to try to not let the presence of sunglasses interfere with their memory for the study faces.

The test consisted of the presentation of 16 study and 16 new faces. (The first two and the last three faces of the study series were used as primacy and recency buffers and were not tested.) Half of the old and half of the new faces were normal, and half were wearing sunglasses. This manipulation was counterbalanced across subjects. The test faces were presented in a random order with the following constraints: Each half of the test series consisted of four old normal faces and four old faces with sunglasses and four new normal faces and four new faces with sunglasses, and in each half of the test series, four of the old test faces had been shown in the first half of the study series and four had been shown in the last half of the study series. Each test face was presented for $5 \mathrm{sec}$. Subjects made their recognition decisions by circling "new," "remember," or "know" on a response sheet.

\section{Results and Discussion}

The mean probabilities of old responses and the separate proportions of remember and know responses for new and old faces with and without sunglasses are shown in Table 1. The data are arranged in Table 1 so that the mirror effect is evidenced by an increase in the means from left to right.

The .05 level of reliability was adopted for all statistical comparisons. Analyses based on proportion of old responses showed that the sunglasses manipulation produced a mirror effect. The hit rate was greater for normal faces than for faces with sunglasses $[t(49)=3.46]$, and the false alarm rate was greater for new faces wearing sunglasses than for normal new faces $[t(49)=2.99]$. The hit rate advantage for normal faces was reflected entirely in remember responses $[t(49)=6.75]$. For know responses, the hit rate was greater for faces with sunglasses $[t(49)=$ 4.27]. The higher false alarm rate for new faces wearing sunglasses was largely due to know responses $[t(49)=$ 2.29]. The difference in false alarm rates for remember responses was not reliable $[t(49)=1.96]$, but this aspect of the results must be interpreted with caution due to the relatively low false alarm rate for remember responses.

Following Donaldson (1996), $A^{\prime}$ and $B_{D}^{\prime \prime}$ were calculated for old decisions and remember responses for each

Table 1

Mean Proportions of Old, Remember, and Know Responses for New and Old Tests of Normal Faces (NSG) and Faces With Sunglasses (SG) for Experiment 1

Test

\begin{tabular}{lccccc}
\cline { 2 - 3 } \cline { 5 - 6 } Response & \multicolumn{2}{c}{ New } & & \multicolumn{2}{c}{ Old } \\
\cline { 2 - 3 } \cline { 5 - 6 } & NSG & SG & & SG & NSG \\
\hline Old & .20 & .29 & & .78 & .87 \\
Remember & .05 & .08 & & .47 & .70 \\
Know & .15 & .21 & & .31 & .18 \\
\hline
\end{tabular}

Table 2

Mean Estimates of $A^{\prime}$ and $B_{b}^{\prime \prime}$ for Overall Old Responses

and Remember Responses for Normal Test Faces (NSG) and Faces With Sunglasses (SG) for Experiment 1

\begin{tabular}{llrlrr} 
& \multicolumn{5}{c}{ Test } \\
\cline { 2 - 3 } \cline { 5 - 6 } Response & \multicolumn{2}{c}{ NSG } & & \multicolumn{2}{c}{ SG } \\
\cline { 2 - 3 } \cline { 5 - 6 } & $A^{\prime}$ & $B_{D}^{\prime \prime}$ & & $A^{\prime}$ & $B_{D}^{\prime \prime}$ \\
\hline Old & .90 & -.22 & & .83 & -.15 \\
Remember & .90 & .69 & .81 & .78 \\
\hline
\end{tabular}

subject. The means of these estimates are given in Table 2. A $2 \times 2$ analysis of variance (ANOVA) based on $A^{\prime}$ confirmed the discrimination advantage for normal test faces $\left[F(1,49)=39.0, M S_{e}=.009, p<.001\right]$. There was no reliable difference between overall old responses and remember responses, and no interaction between these variables $(F \mathrm{~S}<1)$. The same analysis for $B_{D}^{\prime \prime}$ showed that the decision criterion was greater for remember responses than for overall old responses $\left[F(1,49)=128.2, M S_{\mathrm{e}}=.33, p<\right.$ $.001]$. The criterion did not differ reliably between normal faces and faces with sunglasses, and there was no interaction between response and type of test face $(F \mathrm{~S}<1)$.

The results of Experiment 1 demonstrate that the sunglasses manipulation introduced at test was successful in producing a mirror effect. Moreover, the observed mirror effect was prototypical by Hintzman et al.'s (1994) definition; the introduction of sunglasses at test decreased discriminability with little or no difference in bias. In addition, the pattern of results for remember and know responses replicated the results of Hockley (1996) and was also consistent with the signal detection analysis reported by Donaldson (1996). Interpretations of the results of Experiment 1 are considered after the following two experiments are described. These experiments were designed to assess the replicability and generalizability of the results of Experiment 1.

\section{EXPERIMENT 2}

In Experiment 2, presentation of the stimuli and response recording were controlled by laboratory computers, which allowed for better control over randomization and presentation rates and permitted the measurement of response latency. One group of subjects studied normal faces, and recognition memory was tested for faces with and without sunglasses. This group provides a replication of Experiment 1. A second group of subjects studied faces wearing sunglasses, and recognition was tested for faces with and without sunglasses. The question of interest in this condition was whether or not a mirror effect would be found, and if so, whether the recognition advantage would favor normal faces or the studied faces with sunglasses.

To account for the mirror effect found in Experiment 1, Hintzman's (1994) test-trial increment rescaling view must assume that the increment in strength due to relearning at test is less for faces with sunglasses than for normal faces. Thus, this view makes the prediction that faces that are studied with sunglasses will not be as well remembered 
as normal faces, and a mirror effect should be found showing a recognition advantage for normal faces. If, however, faces studied with sunglasses are recognized more accurately than normal faces, then response bias accounts of the mirror effect, such as Greene's (1996) response distribution hypothesis, would predict a mirror effect favoring faces wearing sunglasses.

\section{Method}

Subjects. There were 38 introductory psychology students in each study condition. They received course credit for participation.

Apparatus and Stimuli. Laboratory computers were used to order and display the study and test series and record responses. The slides used in Experiment 1 were scanned and digitized for display on 14-in. color monitors. Subjects used the "/" and "z" keys on the right and the left of the keyboard for making both old/new decisions and remember/know responses. The keyboards were fitted with opaque plastic covers that exposed only the response keys.

Procedure. One group of subjects studied a set of normal faces and the other group studied faces wearing sunglasses. For both groups, half of the old and half of the new test faces were normal and half were shown with sunglasses. The old and new faces with and without sunglasses were selected randomly for each subject, and subjects saw a different random presentation of the study and test series. Study faces were presented for $1 \mathrm{sec}$ with a 0.5 -sec blank interval between presentations.

Following the study list, subjects were informed about the nature of the test and given the instructions concerning remember and know responses used in Experiment 1. They were told that the test faces would appear both normally and wearing sunglasses but that they should base their recognition decision on whether the test face had appeared in the study set. Subjects were asked to make their recognition decision both as accurately and as quickly as possible, with the emphasis placed on accuracy. The instructions took approximately $5 \mathrm{~min}$ and then subjects initiated the test list.

Subjects first made an old/new recognition decision. Old decisions were followed by a remember/know response. The required decision was cued on the monitor under the test face with a reminder of which key to press for each response. The assignment of keys and responses was counterbalanced over subjects in each group. Response latency was measured from the onset of the test face to the old/new response. In all other respects, the procedure of Experiment 2 was the same as in Experiment 1.

\section{Results and Discussion}

The mean proportions of old responses for each study and test condition are presented in Table 3. A 2 (sun-

Table 3

Mean Proportions (P) of Old, Remember, and Know Responses, and Mean Remember and Know Response Times (RT) in Milliseconds for the Study and Test Sunglasses (SG) and No Sunglasses (NSG) Conditions of Experiment 2

\begin{tabular}{|c|c|c|c|c|c|c|c|c|}
\hline \multirow[b]{4}{*}{ Response } & \multicolumn{8}{|c|}{ Test } \\
\hline & \multicolumn{4}{|c|}{ New } & \multicolumn{4}{|c|}{ Old } \\
\hline & \multicolumn{2}{|c|}{ NSG } & \multicolumn{2}{|c|}{ SG } & \multicolumn{2}{|c|}{ SG } & \multicolumn{2}{|c|}{ NSG } \\
\hline & $\mathrm{P}$ & RT & $\mathrm{P}$ & RT & $\mathrm{P}$ & RT & $P$ & $\mathrm{RT}$ \\
\hline \multicolumn{9}{|l|}{ Study NSG } \\
\hline Old & .24 & & .29 & & .70 & & .81 & \\
\hline Remember & .11 & 2,949 & .14 & 3,099 & .54 & 1,837 & .61 & 1,816 \\
\hline Know & .13 & 3,034 & .15 & 3,198 & .16 & 2,946 & .20 & 2,746 \\
\hline \multicolumn{9}{|l|}{ Study SG } \\
\hline Old & .27 & & .30 & & .80 & & .67 & \\
\hline Remember & .09 & 3,821 & .14 & 2,595 & .63 & 1,760 & .41 & 1,935 \\
\hline Know & .18 & 3.736 & .16 & 4,631 & .17 & 2,272 & .26 & 2,939 \\
\hline
\end{tabular}

glasses or no sunglasses at study) $\times 2$ (sunglasses or no sunglasses at test) $\times 2$ (old vs. new test probes) mixedfactor ANOVA based on proportion of old responses showed that the main effects of study $[F(1,74)<1]$ and test condition $\left[F(1,74)=1.73, M S_{\mathrm{e}}=1.83, p=.19\right]$ did not approach significance. Not surprisingly, the overall hit rate was greater than the false alarm rate $[F(1,74)=$ 303.9, $\left.M S_{\mathrm{e}}=3.5, p<.001\right]$. The interactions between study condition and type of test probe and test condition and test probe were not reliable $\left(F_{\mathrm{s}}<1\right)$. The interactions between study and test condition $\left[F(1,74)=7.13, M S_{\mathrm{e}}=\right.$ $1.83, p=.009]$ and between study condition, test condition, and probe type $\left[F(1,74)=16.14, M S_{\mathrm{e}}=1.34, p<\right.$ $.001]$ were significant. Thus, performance in each study and test condition was comparable, and accuracy was greater when the test condition matched the study condition, except for negative test probes in the study condition for faces with sunglasses.

For the group that studied normal faces, the pattern of old responses showed a mirror effect. The hit rate was higher for normal faces than for faces with sunglasses $[t(37)=3.22]$. The false alarm rate was lower for normal faces than for faces with sunglasses, but this difference did not reach statistical significance $[t(37)=1.60]$. A greater overall difference in hit rates was seen in remember responses than in know responses; however, neither the difference in remember responses $[t(37)=1.53]$ nor the difference in know responses $[t(37)=1.05]$ was reliable. The modest difference in overall false alarm rates was due to small differences in both remember and know responses, but neither of these differences approached statistical significance.

The results of the group that studied faces wearing sunglasses did not show a mirror effect pattern. The overall hit rate was reliably greater for faces with sunglasses $[t(37)=3.20]$. The overall false alarm rate was also greater for faces with sunglasses, but this difference did not approach significance $[t(37)=0.75]$. The hit rate advantage for faces with sunglasses was entirely due to a difference in remember responses $[t(37)=4.81]$; the hit rate for know responses was greater for normal faces $[t(37)=2.60]$. The differences in false alarms for remember responses $[t(37)=1.75]$ and for know responses $[t(37)=0.88]$ were not reliable.

Mean response latencies for remember and know responses for each study and test condition are also shown in Table 3. Because of the unequal number of observations per condition and subject, no statistical analyses were carried out on these data. However, the pattern of results for response latency was consistent with the pattern of results found for accuracy. Furthermore, the mean latencies for know responses were generally slower than those for remember responses, consistent with the results found by Dewhurst and Conway (1994), Consoli (1996), and Hockley (1996).

The estimates for $A^{\prime}$ and $B_{D}^{\prime \prime}$ were calculated separately for old and remember responses for each study and test condition and are given in Table 4. A 2 (study condition) $\times 2$ (test condition) $\times 2$ (old vs. remember responses) 
Table 4

Estimated Values of $A^{\prime}$ and $B_{b}^{\prime \prime}$ for Old and Remember Responses for the Study and Test Normal (NSG) and Sunglasses (SG) Conditions of Experiment 2

\begin{tabular}{|c|c|c|c|c|}
\hline \multirow[b]{3}{*}{ Response } & \multicolumn{4}{|c|}{ Test } \\
\hline & \multicolumn{2}{|c|}{ NSG } & \multicolumn{2}{|c|}{ SG } \\
\hline & $\overline{A^{\prime}}$ & $B_{D}^{\prime \prime}$ & $\overline{A^{\prime}}$ & $B_{D}^{\prime \prime}$ \\
\hline \multicolumn{5}{|l|}{ Study NSG } \\
\hline Old & .85 & -.03 & .78 & .01 \\
\hline Remember & .80 & .61 & .77 & .54 \\
\hline \multicolumn{5}{|l|}{ Study SG } \\
\hline Old & .76 & .18 & .82 & -.21 \\
\hline Remember & .74 & .82 & .79 & .41 \\
\hline
\end{tabular}

ANOVA for $A^{\prime}$ showed that the main effects of study condition $[F(1,74)<1]$, test condition $[F(1,74)<1]$, and type of response $\left[F(1,74)=2.00, M S_{\mathrm{e}}=.03, p=.16\right]$ were not reliable. The only significant interaction was between study condition and test condition $\left[F(1,74)=8.15, M S_{\mathrm{e}}=\right.$ $.03, p=.006]$. Thus, the level of accuracy was similar in each study and test condition, and accuracy was greatest when the test condition matched the study condition.

In the same analysis based on mean estimates of $B_{D}^{\prime \prime}$, the main effects of test condition $\left[F(1,74)=7.14, M S_{\mathrm{e}}=\right.$ $.46, p=.01]$, type of response $\left[F(1,74)=131.0, M S_{\mathrm{e}}=\right.$ $.21, p<.001]$, and the interaction between study condition and response $\left[F(1,74)=5.96, M S_{\mathrm{e}}=.46, p=.02\right]$ were all significant. Neither the main effect of study nor any other interaction approached significance $\left(\right.$ all $\left.F_{\mathrm{S}}<1\right)$. The decision criterion was greater for remember responses than for overall old responses, and was greater for normal test faces than for test faces with sunglasses, especially when subjects studied faces wearing sunglasses.

The overall pattern of results for the group that studied normal faces replicated the mirror effect found in Experiment 1 . In contrast, the group that studied faces wearing sunglasses did not show a mirror effect. This group did show a hit rate advantage for test faces with sunglasses, but there was no corresponding advantage for new test faces with sunglasses. This result contradicts the predictions derived from Hintzman's (1994) test-trial increment rescaling and Greene's (1996) response distribution accounts of the mirror effect.

\section{EXPERIMENT 3}

Experiment 3 was a replication of Experiment 2. A sure/unsure confidence response procedure was used in Experiment 3 to allow a comparison between confidence and remember/know responses.

\footnotetext{
Method

Subjects. There were 34 students in the normal faces study condition and 36 subjects in the faces with sunglasses study condition.

Apparatus and Stimuli. The apparatus and stimuli were the same as those used in Experiment 2.
}

Procedure. The procedure was identical to that of Experiment 2 except that after subjects made an old/new response, they made a sure/unsure judgment to indicate their level of confidence in their old or new recognition decision.

\section{Results and Discussion}

The mean proportions of old responses and the separate proportions of sure and unsure responses for each study and test condition are given in Table 5. A 2 (sunglasses or no sunglasses at study) $\times 2$ (sunglasses or no sunglasses at test) $\times 2$ (old vs. new test probe) mixedfactor ANOVA was calculated on the basis of the proportion of old responses. As expected, the overall hit rate was greater than the false alarm rate $[F(1,68)=425.6$, $\left.M S_{\mathrm{e}}=2.44, p<.001\right]$. The main effects of study $[F(1,68)$ $\left.=3.21, M S_{\mathrm{e}}=2.89, p=.08\right]$ and test condition $[F(1,68)$ $\left.=1.95, M S_{\mathrm{e}}=1.97, p=.17\right]$ were not reliable. The interactions between study condition and type of test probe $\left[F(1,68)=1.37, M S_{\mathrm{e}}=2.44, p=.25\right]$ and test condition and type of probe $\left[F(1,68)=2.43, M S_{\mathrm{e}}=1.23, p=.12\right]$ were not significant either. The interaction between study and test condition did not reach significance $[F(1,68)=$ 3.36, $\left.M S_{\mathrm{e}}=1.97, p=.07\right]$, but the interaction between study condition, test condition, and type of test probe was highly reliable $\left[F(1,68)=31.79, M S_{\mathrm{e}}=1.23, p<.001\right]$. Thus, as was found in Experiment 2, overall performance in each study and test condition was comparable, and accuracy was greater when the test condition matched the study condition except for negative test probes in the study condition for faces with sunglasses.

The group that studied normal faces again showed the mirror effect pattern. The hit rate was significantly higher $[t(33)=3.08]$ and the false alarm rate was reliably lower $[t(33)=3.20]$ for normal faces than for faces with sunglasses. The difference in hit rates was seen only in sure responses $[t(33)=3.20]$. The proportion of unsure responses was greater for faces with sunglasses, but this difference was not reliable $[t(33)=0.61]$. The difference in false alarm rates was seen to a greater extent in unsure responses than in sure responses; this difference was re-

Table 5

Mean Proportions (P) of Old, Sure, and Unsure Responses and Mean Sure and Unsure Response Times (RT) in Milliseconds for the Study and Test Sunglasses (SG) and No Sunglasses (NSG) Conditions of Experiment 3

\begin{tabular}{|c|c|c|c|c|c|c|c|c|}
\hline \multirow[b]{4}{*}{ Response } & \multicolumn{8}{|c|}{ Test } \\
\hline & \multicolumn{4}{|c|}{ New } & \multicolumn{4}{|c|}{ Old } \\
\hline & \multicolumn{2}{|c|}{ NSG } & \multicolumn{2}{|c|}{ SG } & \multicolumn{2}{|c|}{ SG } & \multicolumn{2}{|c|}{ NSG } \\
\hline & $P$ & $\mathrm{RT}$ & $P$ & RT & $P$ & RT & $\mathrm{P}$ & RT \\
\hline \multicolumn{9}{|c|}{ Study NSG } \\
\hline Old & .18 & & .29 & & .63 & & .75 & \\
\hline Sure & .12 & 2,702 & .16 & 2,895 & .52 & 2,286 & .67 & 1,812 \\
\hline Unsure & .06 & 2,953 & .13 & 3,306 & .11 & 4,336 & .08 & 3,872 \\
\hline \multicolumn{9}{|l|}{ Study SG } \\
\hline Old & .25 & & .25 & & .83 & & .70 & \\
\hline Sure & .16 & 2,450 & .18 & 1,907 & .75 & 1,433 & .60 & 1,667 \\
\hline Unsure & .09 & 2,734 & .07 & 2,397 & .08 & 2,419 & .09 & 3,168 \\
\hline
\end{tabular}


liable for unsure responses $[t(33)=3.59]$ but was not significant for sure responses $[t(33)=1.50]$.

The group that studied faces with sunglasses did not show a mirror effect. The overall hit rate was significantly greater for faces wearing sunglasses than for normal faces $[t(35)=4.33]$, but the false alarm rate was the same for the two types of test probes. The hit rate difference was seen only in sure responses $[t(35)=3.78]$. The difference in hit rates for unsure responses $[t(35)=.60]$ and the difference in false alarm rates for sure responses $[t(35)=$ $.69]$ and unsure responses $[t(35)=.87]$ did not approach significance.

The mean response times for sure and unsure responses in each study and test condition are also given in Table 5. The pattern of mean response times was generally consistent with the pattern of results for accuracy. Sure responses were also faster, on average, than unsure responses.

The estimates for $A^{\prime}$ and $B_{D}^{\prime \prime}$ both for overall old responses and for sure responses for each study and test condition are given in Table 6. A 2 (study condition) $\times 2$ (test condition) $\times 2$ (old vs. remember responses) ANOVA for $A^{\prime}$ showed that the main effects of study condition $\left[F(1,68)=2.00, M S_{\mathrm{e}}=.04, p=.16\right]$ and type of response $\left[F(1,68)=3.21, M S_{\mathrm{e}}=.04, p=.08\right]$ were not significant, and neither was their interaction $[F(1,68)<1]$. The main effect of test condition reached significance $[F(1,68)=$ $\left.4.01, M S_{\mathrm{e}}=.02, p=.05\right]$, but was qualified by the highly significant interaction between the study and test conditions $\left[F(1,68)=18.78, M S_{\mathrm{e}}=.02, p<.001\right]$. No other interaction was significant. As in Experiment 2, the level of accuracy was similar for each study condition, and accuracy was greatest when the test condition matched the study condition.

The same analysis based on mean estimates of $B_{D}^{\prime \prime}$ showed a significant main effect of type of response $\left[F(1,74)=131.0, M S_{\mathrm{e}}=.21, p<.001\right]$ such that the decision criterion was higher for remember than for old responses. Criteria values tended to be lower for the group that studied faces with sunglasses than for the group that studied normal faces; this trend approached but did not reach statistical significance $\left[F(1,68)=3.54, M S_{\mathrm{e}}=.79\right.$, $p=.06]$. The main effect of test condition $[F(1,68)=2.98$, $\left.M S_{\mathrm{e}}=.54, p=.09\right]$ was also not significant, and neither were the interactions between study and test conditions $\left[F(1,68)=2.74, M S_{\mathrm{e}}=.54, p=.09\right]$, study condition and

Table 6

Estimated Values of $A^{\prime}$ And $B_{D}^{\prime \prime}$ for Old and Sure Responses for the Study and Test Normal (NSG) and Sunglasses (SG) Conditions of Experiment 3

\begin{tabular}{|c|c|c|c|c|}
\hline \multirow[b]{3}{*}{ Response } & \multicolumn{4}{|c|}{ Test } \\
\hline & \multicolumn{2}{|c|}{ NSG } & \multicolumn{2}{|c|}{$\mathrm{SG}$} \\
\hline & $\overline{A^{\prime}}$ & $B_{D}^{\prime \prime}$ & $\overline{A^{\prime}}$ & $B_{D}^{\prime \prime}$ \\
\hline \multicolumn{5}{|l|}{ Study NSG } \\
\hline Old & .85 & .23 & .74 & .20 \\
\hline Sure & .86 & .54 & .77 & .59 \\
\hline \multicolumn{5}{|l|}{ Study SG } \\
\hline Old & .80 & .20 & .86 & -.12 \\
\hline Sure & .83 & .47 & .85 & .20 \\
\hline
\end{tabular}

type of response $[F(1,68)<1]$, or test condition and response $\left[F(1,68)=1.33, M S_{\mathrm{e}}=.05, p=.25\right]$. The threeway interaction $[F(1,68)<1]$ was also not significant.

The results of Experiment 3 replicated the findings of Experiment 2 in all important respects. Furthermore, Experiment 3 showed that a sure/unsure confidence judgment procedure gives rise to a similar pattern of results as the remember/know response procedure used in Experiments 1 and 2 .

\section{GENERAL DISCUSSION}

The results of the present experiments demonstrate that a mirror effect can be obtained for a stimulus manipulation introduced at test. When subjects studied a series of normal faces, the hit rate was greater and the false alarm rate was less for normal test faces than for test faces with sunglasses. Experiments 2 and 3 also showed that when subjects studied faces wearing sunglasses, no mirror effect was observed. The hit rate was greater for studied faces with sunglasses than for normal faces, but no consistent or reliable difference was obtained for the false alarm rates.

The results of the two study conditions contrasted in Experiments 2 and 3 support the general principle of encoding specificity (e.g., Tulving \& Thomson, 1973) since memory was best when the information provided at test most closely matched the information presented at study. Presumably, when normal faces were shown at study, subjects paid particular attention to the features of the eyes. When these features were covered by sunglasses at test, recognition memory for the faces suffered. In Experiments 2 and 3 , when faces wearing sunglasses were shown at study, subjects presumably emphasized facial features other than the eyes that supported recognition memory for the studied faces.

Studies that have examined how recognition accuracy is affected by the omission or alteration of features within Caucasian faces suggest that upper features contribute more to recognition than do lower features (Davies, Ellis, $\&$ Shepherd, 1977). Studies that have used subjective reports, verbal descriptions, and analyses of inspection strategies also show the importance of the features of hair and eyes for Caucasian faces (see Shepherd, Davies, \& Ellis, 1981, for a review of studies concerning cue saliency in identification and recognition of faces).

The present demonstration of the mirror effect for faces with and without sunglasses may be related to the typicality effect for face recognition, which, as Vokey and Read (1992) have noted, is another stimulus variable that gives rise to the mirror effect. The typicality effect refers to the finding that recognition memory for atypical or unusual faces is greater than for typical faces (e.g., Bartlett, Hurry, \& Thorley, 1984; Courtois \& Mueller, 1981; Going \& Read, 1974; Light, Kayra-Stuart, \& Hollander, 1979). This effect is seen in both a lower false alarm rate and, less reliably, a higher hit rate for atypical than for typical faces (see Shapiro \& Penrod, 1986, for a meta- 
analysis of this effect). It is possible that sunglasses may serve to reduce atypical facial features or increase the similarity between faces.

The present results have several important implications for theoretical interpretations of the mirror effect. These implications are considered below with respect to the three different classes of theories that have been proposed to account for the mirror effect.

\section{Rescaling Theories}

The fact that a mirror effect was observed for the sunglasses manipulation introduced at test following the study of normal faces demonstrates that specific prior experience with the classes or types of stimuli is not necessary to produce the mirror effect. This is potentially problematic for rescaling theories of the mirror effect, such as attention-likelihood theory (see, e.g., Glanzer \& Adams, 1990), that require subjects to compute or estimate separate familiarity distributions for the different classes of stimuli.

Attention-likelihood theory, as described by Glanzer et al. (1991; Glanzer et al., 1993), is a feature-sampling theory in which stimuli are represented by sets of features. Each feature is either marked or unmarked. Stimuli come with a proportion of features already marked due to preexperimental experience with the item or from the marking of other items with overlapping features in the experiment. Unmarked features that are attended to during study become marked. Studied items from the more memorable stimulus class have a greater proportion of marked features than studied items from the less memorable stimulus class.

The subject (or recognition system) has two pieces of information about each test item: the number of features sampled, and the proportion of sampled features that are marked, $x$. The subject is also assumed to have some background information about how much marking a new item might have and how much marking an old item of that type might have. The subject then estimates the probability that an old item of that type will have $x$ marked features and the probability that a new item will have $x$ marked features. A likelihood ratio is computed on the basis of these estimates. Subjects then base their recognition decisions on the likelihood ratios that compare the probability of a test item's being old with the probability that it is new.

It is assumed that subjects derive these ratios "on the basis of their experience in the experiment" (Kim \& Glanzer, 1994, p. 207). In the present experiments, subjects were not given an opportunity to acquire background information about how much marking new and old faces wearing sunglasses might have, since the sunglasses manipulation was not introduced until test. It might be argued that subjects would have preexperimental experience viewing faces with sunglasses, and they could use this experience in forming their estimates. It is not obvious, however, how easily or how well subjects could use such general prior experience to derive distribution estimates for the specific novel faces presented in the experiment.

Perhaps more problematic for attention-likelihood theory is the failure to find a mirror effect when subjects studied faces wearing sunglasses in Experiments 2 and 3 , even though faces with sunglasses were responded to more accurately than normal faces. Why would subjects generate likelihood ratios that would produce a mirror effect in one study condition and not the other?

Hintzman (1994) proposed test-trial increment rescaling as an alternative way for subjects to appropriately order the underlying distributions. This account does not require subjects to generate familiarity distributions for the separate classes of stimuli since the rescaling is made on an item-by-item basis at test. The present results also pose a problem for this interpretation of the mirror effect. In test-trial increment rescaling, subjects relearn the item at test and use the increment in strength after relearning to estimate the study-trial increment in strength. To account for the present demonstration of the mirror effect, it must be assumed that when subjects relearned the probes at test, the strength increment was greater for normal faces than for faces wearing sunglasses.

Test-trial increment rescaling, therefore, must assume that normal faces are learned or encoded with a greater strength than faces with sunglasses. When subjects studied faces with sunglasses, however, they correctly recognized these faces more accurately than normal faces. Moreover, discrimination as measured by $A^{\prime}$ did not differ reliably between the two study conditions, indicating that faces studied with and without sunglasses were equally memorable. Thus, Hintzman's (1994) test-trial increment rescaling account of the mirror effect cannot explain the present pattern of results.

\section{Response Bias Theories}

Response bias accounts would seem to be well suited to provide an explanation of the present demonstration of the mirror effect because the stimulus manipulation was highly salient and it would be easy for subjects to adopt different responses strategies for the two classes of stimuli. According to Greene's (1996) response distribution explanation of the mirror effect, subjects try to balance positive responses across the different classes of stimuli. That is, when subjects "are faced with two easily discriminable sets of items, they try to give equal numbers of positive responses to both sets" (Greene, 1996, p. 691). Subjects have more difficulty in correctly distributing old responses for the less memorable stimulus class, resulting in a lower hit rate and a higher false alarm rate for items of this class.

Although response distribution can account for the present mirror effect, the assumption that subjects try to balance old responses across the two types of test stimuli would appear to be a somewhat unusual strategy for subjects to adopt in Experiments 1 and 2, in which the instructions placed a strong emphasis on distinguishing 
between remember and know recognition decisions. Nevertheless, it is not entirely unreasonable to assume that subjects may have chosen to be more concerned about the frequency of their old decisions rather than the frequency of their remember or know responses across the two types of test stimuli.

More problematic for the response distribution account is the finding that subjects did not attempt to balance old decisions when faces with sunglasses were studied. In this condition, the hit rate was greater for faces with sunglasses, but the false alarm rates did not differ for normal faces and faces with sunglasses. Thus, subjects made more old responses to faces with sunglasses than to normal faces. There is no obvious or logical reason to explain why subjects would not adopt a similar response distribution strategy in both study conditions. It is also relevant to note in this regard that Glanzer, Kim, and Adams (1998), in a recent study designed to directly test the response distribution account, have shown that the mirror effect can be obtained in the absence of response equalization. Their experiments also showed that subjects in general do not attempt to equalize positive responses for different stimulus classes.

In Hirshman's (1995) response bias, or criterion shift, view of the mirror effect, subjects adopt a higher decision criterion for items from the more memorable class because the mean of the old distribution for these items is higher than the mean of the old distribution for items of the less memorable class. Appropriate placement of the criteria for the two classes of items can produce a higher hit rate and a lower false alarm rate for items from the more memorable stimulus class. The criteria estimates in the study conditions of the present experiments that showed a mirror effect did not change in this manner. Rather, the criteria estimates for test faces with and without sunglasses were similar, conforming to Hintzman et al.'s (1994) definition of the prototypical mirror effect.

\section{Two-Component View}

It was noted earlier in this discussion that the mirror effect for faces with and without sunglasses may be related to the typicality effect for face recognition. Both Light et al. (1979) and Vokey and Read (1992) have argued that two different factors are needed to explain the typicality effect for face recognition - a general familiarity component derived from face similarity that is responsible for differences in false alarms, and a memory-specific component that determines differences in hit rates.

The two-component view of the mirror effect proposed by Hockley (1996) is similar to Vokey and Read's (1992) two-factor account of the typicality effect for face recognition. According to the two-component view, differences in hit rates between two classes of stimuli are due to differences in recollection, whereas the higher false alarm rate for the less memorable stimulus class is due to greater familiarity. In a two-component interpretation of the present demonstration of the mirror effect, the difference in hit rates occurred because old faces presented normally are easier to recollect because they more closely matched the encoded representations of the studied faces than did test faces wearing sunglasses. The increase in false alarm rates was because new faces wearing sunglasses appeared more familiar than normal faces. This increase in familiarity could arise because when subjects studied normal faces, they emphasized features related to the eyes. At test, new faces that included features of the eyes would not appear to be very familiar because they would have more features that mismatched the studied faces. In contrast, new faces wearing sunglasses would seem more familiar because they have far fewer mismatching features and therefore would be harder to reject.

When subjects studied faces wearing sunglasses, a mirror effect was not found because there was no difference in the false alarm rates between test faces with and without sunglasses. When subjects studied faces with sunglasses, they must have emphasized facial features other than the eyes. Thus, at test, features of the eyes would not be as important in the discrimination of old and new faces. New faces with and without sunglasses would have a similar number of matching features and thus give rise to similar false alarm rates.

The pattern of remember and know responses observed in Experiments 1 and 2 is consistent with the twocomponent account of the mirror effect; the hit rate advantage for normal faces was entirely reflected in remember responses, whereas differences in false alarm rates were largely seen in know responses.

A similar pattern of results, however, was also obtained with sure/unsure confidence judgments in Experiment 3. This indicates that the remember/know responses in Experiments 1 and 2 are highly correlated with confidence. As Gardiner and Java (1990) have noted, it is not surprising to find a strong correspondence between confidence and recollective experience because recollection would be expected to produce strong feelings of confidence. Conversely, it is also reasonable to expect that the sense of familiarity that is assumed to provide the basis of know responses may vary in intensity and thus know responses would, on average, be associated with lower judgments of confidence than would remember responses.

Donaldson (1996) has argued for a single-factor interpretation of remember/know responses. He showed that a majority of results employing this response procedure were consistent with a two-criteria signal detection analysis. The present results were also consistent with this analysis since discrimination was equivalent for overall recognition performance and for recognition performance conditionalized on remember responses, and the decision criterion for remember responses was significantly greater than the criterion for overall recognition. Thus the present results extend the generality of Donaldson's (1996) meta-analysis of remember versus know responses to recognition of faces.

Signal detection is a powerful theory, and it is perhaps not surprising that this analysis can provide a good fit to both confidence judgments and remember/know re- 
sponses. Nevertheless, the fact that this single-factor theory can provide a description of remember/know responses does not in and of itself preclude the possibility that more than one component of memory underlies recognition performance.

\section{Summary}

The present study demonstrated a mirror effect for a stimulus manipulation introduced at test. When subjects studied a normal set of faces, the hit rate was higher and the false alarm rate was lower for normal test faces than for old and new test faces wearing sunglasses. In contrast, when subjects studied faces wearing sunglasses, the hit rate was higher for test faces with sunglasses, but no reliable difference in false alarm rates was found between normal faces and faces wearing sunglasses. This pattern of results poses problems for most current single-factor theories of the mirror effect.

Two-factor theories offer an alternative approach to account for the mirror effect (Bartlett et al., 1995; Hintzman, 1988; Hockley, 1996; Hoshino, 1991; Vokey \& Read, 1992; Wixted, 1992). The two-component view, which assumes that two different bases of recognition memory, familiarity and recollection, are responsible for the differences in hit and false alarm rates, provides a reasonable interpretation of the present findings. This view also provides a natural explanation of the finding that Alzheimer's patients, who suffer deficits in recollection and source memory, do not show a mirror effect (Bäckman \& Herlitz, 1990; Bartlett et al., 1995). More generally, this view is consistent with the growing body of evidence that supports a dual-process view of recognition memory.

\section{REFERENCES}

Bäckman, L., \& HerlitZ, A. (1990). The relationship between prior knowledge and face recognition memory in normal aging and Alzheimer's disease. Journal of Gerontology, 45, 94-100.

Bartlett, J. C., HalPerN, A. R., \& Dowling, W. J. (1995). Recognition of familiar and unfamiliar melodies in normal aging and $\mathrm{Alz}$ heimer's disease. Memory \& Cognition, 23, 531-546.

Bartlett, J. C., Hurry, S., \& ThORLEy, W. (1984). Typicality and familiarity of faces. Memory \& Cognition, 12, 219-228.

CONSOLI, A. (1996). Item versus associative information: A comparison of forgetting rates with and without recollective experience. Unpublished master's thesis, Wilfrid Laurier University.

Conway, M. A., \& Dewhurst, S. A. (1995). Remembering, familiarity, and source monitoring. Quarterly Journal of Experimental Psychology, 48A, 125-140.

COURTOIS, M. R., \& MUELLER, J. H. (1981). Target and distractor typicality in facial recognition. Journal of Applied Psychology, 66, 639-645.

Davies, G. M., Ellis, H. D., \& Shepherd, J. W. (1977). Cue saliency in faces as assessed by the photofit technique. Perception, 6, 262-269.

Dewhurst, S. A., \& Conway, M. A. (1994). Pictures, images, and recollective experience. Journal of Experimental Psychology: Learning, Memory, \& Cognition, 20, 1088-1098.

DONALDSON, W. (1992). Measuring recognition memory. Journal of Experimental Psychology: General, 121, 275-277.

DONALDSON, W. (1993). Accuracy of $d^{\prime}$ and $A^{\prime}$ as estimates of sensitivity. Bulletin of the Psychonomic Society, 31, 271-274

DONALDSON, W. (1996). The role of decision processes in remembering and knowing. Memory \& Cognition, 24, 523-533.

GARDINER, J. M. (1988). Functional aspects of recollective experience. Memory \& Cognition, 16, 309-313.
Gardiner, J. M., \& JAVA, R. I. (1990). Recollective experience in word and nonword recognition. Memory \& Cognition, 18, 23-30.

GaRDINER, J. M., \& JAVA, R. I. (1991). Forgetting in recognition memory with and without recollective experience. Memory \& Cognition, 19, 617-623.

GaRDINER, J. M., \& JAVA, R. I. (1993). Recognising and remembering. In A. Collins, S. E. Gathercole, M. A. Conway, \& P. E. Morris (Eds.), Theories of memory (pp. 163-188). Hillsdale, NJ: Erlbaum.

GARDINER, J. M., JAVA, R. I., \& RichaRDSON-KLAVEHN, A. (1996). How level of processing really influences awareness in recognition memory. Canadian Journal of Experimental Psychology, 50, 1 14-122.

Gardiner, J. M., \& PARKIN, A. J. (1990). Attention and recollective experience in recognition memory. Memory \& Cognition, 18, 579-583.

Gillund, G., \& ShifFrin, R. M. (1984). A retrieval model for both recognition and recall. Psychological Review, 91, 1-67.

GLANZER, M., \& ADAMS, J. K. (1985). The mirror effect in recognition memory. Memory \& Cognition, 13, 8-20.

GLANZER, M., \& ADAMS, J. K. (1990). The mirror effect in recognition memory: Data and theory. Journal of Experimental Psychology: Learning, Memory, \& Cognition, 16, 5-16.

Glanzer, M., ADAMS, J. K., \& Iverson, G. [J.] (1991). Forgetting and the mirror effect in recognition memory: Concentering of underlying distributions. Journal of Experimental Psychology: Learning, Memory, \& Cognition, 17, 81-93.

Glanzer, M., Adams, J. K., IVerson, G. J., \& Kim, K. (1993). The regularities of recognition memory. Psychological Review, 100, 546-567.

Glanzer, M., \& Bowles, N. (1976). Analysis of the word frequency effect in recognition memory. Journal of Experimental Psychology: Human Learning \& Memory, 2, 21-31.

GlanZer, M., KIM, K., \& ADAMS, J. K. (1998). Response distribution as an explanation of the mirror effect. Journal of Experimental Psy. chology: Learning, Memory, \& Cognition, 24, 633-644.

GoING, M., \& READ, J. D. (1974). The effect of uniqueness, sex of subject and sex of photograph on facial recognition. Perceptual \& Motor Skills, 39, 109-110.

GreENE, R. L. (1996). Mirror effect in order and associative information: The role of response strategies. Journal of Experimental Psychology: Learning, Memory, \& Cognition, 22, 687-695.

Greene, R. L., \& Thapar, A. (1994). Mirror effect in frequency discrimination. Journal of Experimental Psychology: Learning, Memory, \& Cognition, 20, 946-952.

HiNTZMAN, D. L. (1988). Judgments of frequency and recognition in a multiple-trace memory model. Psychological Review, 95, 528-551.

HINTZMAN, D. L. (1994). On explaining the mirror effect. Journal of Experimental Psychology: Learning, Memory, \& Cognition, 20, 201-205.

Hintzman, D. L., Caulton, D. A., \& Curran, T. (1994). Retrieval constraints and the mirror effect. Journal of Experimental Psychology: Learning, Memory, \& Cognition, 20, 275-289.

HIRSHMAN, E. (1995). Decision processes in recognition memory: Criterion shifts and the list strength paradigm. Journal of Experimental Psychology: Learning, Memory, \& Cognition, 21, 302-313.

Hirshman, E., \& Master, S. (1997). Modeling the conscious correlations of recognition memory: Reflections on the remember-know paradigm. Memory \& Cognition, 25, 345-351.

HOCKLEY, W. E. (1994). Reflections of the mirror effect for item and associative recognition. Memory \& Cognition, 19, 713-722.

HOCKLEY, W. E. (1996, July). The mirror effect: Reflections of two components of recognition memory? Paper presented at the Second International Conference on Memory, Padua.

HoCKLEY, W. E., \& MURDOCK, B. B., JR. (1987). A decision model for accuracy and response latency in recognition memory. Psychological Review, 94, 341-358.

Hoshino, Y. (1991). A bias in favor of the positive response to highfrequency words in recognition memory. Memory \& Cognition, 19, 607-616.

Humphreys, M. S., Bain, J. D., \& Pike, R. (1989). Different ways to cue a coherent memory system: A theory for episodic, semantic, and procedural tasks. Psychological Review, 96, 208-233.

Kim, K., \& Glanzer, M. (1993). Speed versus accuracy instructions, study time, and the mirror effect. Journal of Experimental Psychology: Learning, Memory, \& Cognition, 19, 638-652. 
Kim, K., \& Glanzer, M. (1994). Attention/likelihood theory: Reply to Hintzman (1994). Journal of Experimental Psychology: Learning, Memory, \& Cognition, 20, 206-208.

Kinoshita, S. (1995). The word frequency effect in recognition memory versus repetition priming. Memory \& Cognition, 23, 569-580.

KNOWLTON, B. J., \& SQuiRe, L. R. (1995). Remembering and knowing: Two different expressions of declarative memory. Journal of Experimental Psychology: Learning, Memory, \& Cognition, 21, 699-710.

LECOMPTE, D. C. (1995). Recollective experience in the revelation effect: Separating the contributions of recollection and familiarity. Memory \& Cognition, 23, 324-334.

Light, L. L., Kayra-Stuart, F, \& Hollander, S. (1979). Recognition memory for typical and unusual faces. Journal of Experimental Psychology: Human Learning \& Memory, 5, 212-228.

Luo, C. R. (1993). Enhanced feeling of recognition: Effects of identifying and manipulating test items on recognition memory. Journal of Experimental Psychology: Learning, Memory, \& Cognition, 19, 405-413.

MANDL.ER, G. (1980). Recognizing: The judgment of previous occurrence. Psychological Review, 87, 252-271.

MANDLER, G. (1991). Your face looks familiar but I can't remember your name: A review of dual process theory. In W. E. Hockley \& S. Lewandowsky (Eds.), Relating theory and data: Essays on human memory in honor of Bennet B. Murdock (pp. 207-225). Hillsdale, NJ: Erlbaum.

MURDOCK, B. B., JR. (1982). A theory for the storage and retrieval of item and associative information. Psychological Review, 89, 609-626.

Parkin, A. J., \& Russo, R. (1993). On the origin of functional differences in recollective experience. Memory, 1, 231-237.

Perfect, T. J., Mayes, A. R., Downes, J. J., \& Van Euk, R. (1996). Does context discriminate recollection from familiarity in recognition memory? Quarterly Journal of Experimental Psychology, 49A, 797-813.

Peynircioğlu, Z. F., \& Tekcan, A. İ. (1993). Revelation effect: Effort or priming does not create the sense of familiarity. Journal of Experimental Psychology: Learning, Memory, \& Cognition, 19, 382-388.

RAJARAM, S. (1993). Remembering and knowing: Two means of access to the personal past. Memory \& Cognition, 21, 89-102.

Shapiro, P. N., \& Penrod, S. (1986). Meta-analysis of facial identification studies. Psychological Bulletin, 100, 139-156.

Shepherd, J., Davies, G., \& Ellis, H. (1981). Studies of cue saliency. In G. Davies, H. Ellis, \& J. Shepherd (Eds.), Perceiving and remembering faces (pp. 105-131). London: Academic Press.
STRACK, F., \& ForSTER, J. (1995). Reporting recollective experiences: Direct access to memory systems? Psychological Science, 6, 352-358. Tulving, E. (1985). Memory and consciousness. Canadian Psychology, 26, 1-12.

Tulving, E., \& Thomson, D. M. (1973). Encoding specificity and retrieval processes in episodic memory. Psychological Review, 80, 352-373.

VOKEY, J. R., \& READ, J. D. (1992). Familiarity, memorability, and the effect of typicality on the recognition of faces. Memory \& Cognition, 20, 291-302.

Watkins, M. J., \& PeynircioǦlu, Z. F. (1990). The revelation effect: When disguising test items induces recognition. Journal of Experimental Psychology: Learning, Memory, \& Cognition, 16, 1012-1020.

Westerman, D. L., \& Greene, R. L. (1996). On the generality of the revelation effect. Journal of Experimental Psychology: Learning, Memory, \& Cognition, 22, 1147-1153.

WIXTED, J. T. (1992). Subjective memorability and the mirror effect. Journal of Experimental Psychology: Learning. Memory, \& Cognition, 18, 681-690.

\section{NOTES}

1. We thank Robert Greene for pointing out the prediction based on the revelation effect. Westerman and Greene (1996) noted both that the revelation effect is still poorly understood and that it is not clear how to reconcile this phenomenon with the mirror effect. Although the present results do not help to resolve this problem, they do serve to provide a limitation on the generality of the revelation effect. In demonstrations of this effect, the test probe is eventually revealed to the subject, either by the experimenter or by the subject (e.g., solving an anagram). In contrast, in the present experiments, faces presented at test wearing sunglasses were never revealed to subjects insofar as the normal versions of the faces were not subsequently presented. The revelation effect is aptly named, since the revelation of the test probe appears to be a critical feature of this effect.

2. Both $d^{\prime}$ and $A^{\prime}$ are estimates of recognition performance that are theoretically independent of the decision criterion. $A^{\prime}$ varies from 0 to 1 , with .5 representing chance performance, and is equivalent to percent correct on a two-alternative forced-choice recognition test. Donaldson (1993) showed that $d^{\prime}$ is a slightly better measure when performance is unbiased, and that $A^{\prime}$ is a better measure when criterion changes occur. $B_{D}^{\prime \prime}$ is the measure of the criterion associated with $A^{\prime}$ and ranges from -1 to +1 (Donaldson, 1992). Positive values reflect conservative responding, whereas negative values indicate liberal responding.

(Manuscript received March 28, 1997;

revision accepted for publication September 11, 1997.) 